\title{
Unraveling the enigma: Progress towards understanding the Coronin family of actin regulators
}

\author{
Keefe T. Chan*, Sarah J. Creed", and James E. Bear\# \\ Lineberger Comprehensive Cancer Center and Department of Cell \& Developmental Biology \\ Howard Hughes Medical Institute University of North Carolina at Chapel Hill Chapel Hill, NC \\ 27599 USA
}

\section{Abstract}

Coronins are a conserved family of actin cytoskeleton regulators that promote cell motility and modulate other actin-dependent processes. Although these proteins have been known for twenty years, substantial progress has been made in the last five years towards understanding coronins. Here, we review this progress, place it into the context of what was already known and pose several questions that remain to be addressed. In particular, we cover the emerging consensus about the role of Type I coronins in coordinating the function of Arp $2 / 3$ complex and ADF/cofilin proteins. This coordination plays an important role in leading edge actin dynamics and overall cell motility. Finally, we discuss the roles played by the more exotic coronins of the Type II and III classes in cellular processes away from the leading edge.

\section{A brief natural history of coronins}

Coronins have been reviewed twice on the pages of Trends in Cell Biology, first in 1999 and again in $2006^{1,2}$. Here, we will provide an update on the progress made in the last five years of research on the coronin family. Many interesting new facts have been learned about these proteins, however much remains to be uncovered.

Coronin was originally identified as a component of a contracted myosin-actin preparation from the amoeba Dictyostelium ${ }^{3}$. Using antibodies raised against coronin, this protein was localized to 'crown-like' structures on the dorsal surface of the cells. This led to the name coronin that is derived from the latin root corona for crown. Coronin-null cells display a $50 \%$ reduction in cell migration speed and are impaired in growth, cytokinesis and fluid phase endocytic uptake ${ }^{4,5}$. Readers interested in the discovery of coronin are encouraged to read more about this in a fascinating account recently written by Eugenio de Hostos 6 .

Most coronin proteins have a similar structural arrangement. The defining structural characteristic of this family is the presence of a WD40-repeat containing $\beta$-propeller (Figure 1). This structural motif is found in a wide variety of proteins including many signaling and adaptor proteins, and is generally believed to be a scaffold to support protein-protein interactions ${ }^{7}$. In addition to the $\beta$-propeller, all coronins contain short, highly conserved $\mathrm{N}$ terminal and C-terminal extensions flanking the $\beta$-propeller that may serve to regulate

(C) 2011 Elsevier Ltd. All rights reserved.

${ }^{\#}$ Corresponding author .

*Equal contributors

Publisher's Disclaimer: This is a PDF file of an unedited manuscript that has been accepted for publication. As a service to our customers we are providing this early version of the manuscript. The manuscript will undergo copyediting, typesetting, and review of the resulting proof before it is published in its final citable form. Please note that during the production process errors may be discovered which could affect the content, and all legal disclaimers that apply to the journal pertain. 
coronin interactions and/or stabilize the $\beta$-propeller structure ${ }^{8}$. Coronins also have a highly variable unique region that links the $\beta$-propeller to a coiled-coil domain at the extreme $\mathrm{C}$ terminus. Phylogenetic analysis led us to group mammalian coronin genes into three types (I, II \& III) ${ }^{2}$. The same basic structural arrangement holds true for all coronins of the Type I and II classes, although Type II coronins contain several blocks of conserved residues in predicted loops in the $\beta$-propeller and unique regions that distinguish them from Type I coronins. Type III coronins are unusual in that they have two complete $\beta$-propeller units (including $\mathrm{N}$ - and $\mathrm{C}$-terminal extensions) linked by a sequence predicted to be flexible. These coronins lack a coiled-coil domain, but have a highly acidic region at their $\mathrm{C}$ terminus ${ }^{2}$.

Coronins are truly ancient proteins being found in the majority of eukaryotic lineages 9 . Most organisms contain two types of coronins: a shorter form conforming to the basic Type I/II architecture with a single $\beta$-propeller and a coiled-coil domain and a longer form of the Type III class. Some fungal species, such as Saccharomyces cerevisiae, have only the short form. By sequence comparison, the budding yeast coronin protein, $\mathrm{Crn} 1 \mathrm{p}$, appears to be most closely related to the Type I coronins in vertebrates, but it is important to note that these proteins are separated from their common ancestor by many hundreds of millions of years of evolution and unique properties may have developed in each group to meet speciesspecific needs. In vertebrates, all three classes of coronin are present with the appearance of the Type II class. In mammalian genomes, seven coronin genes are present with four Type I coronins, two Type II coronins and a single Type III coronin. The sequence record of the least studied mammalian coronin, Coro6, has recently been corrected to indicate the correct start site and reading frame, suggesting that this Type I coronin may indeed encode a fulllength coronin protein (http://www.ncbi.nlm.nih.gov/nuccore/NM_032854.3). However, evidence of expression at the protein level and any functional role for this coronin is lacking.

As with many protein families, nomenclature of coronin genes and their protein products is a confusing and somewhat contentious issue (Table 1). This is particularly true of the seven mammalian coronins where multiple labs independently discovered these genes and adopted their own naming conventions. The original nomenclature system proposed by de Hostos in 1999 is still in use by some labs and simply numbers the genes coronin 1-5 ${ }^{1}$. However, the most widely used nomenclature system was developed by the Human Genome Nomenclature Committee (HGNC) in 2001, and these official gene symbols (Coro1 A, 1B, $2 \mathrm{~A}$, etc.) have been adopted for other vertebrate species to identify orthologues. An alternate system was proposed in 2008 by Morgan and Fernandez which again used numbers to identify all coronin genes in the database at that time ${ }^{10}$. This system has not been widely adopted by coronin researchers for a number of reasons including the confusion arising from re-numbering existing genes and failure to respect the naming conventions of model organism genomes. We will use the HGNC nomenclature for the remainder of this review.

\section{The mechanism of Type I coronin function}

A great deal of progress has been made towards understanding the mechanism of Type I coronins in the last five years. Some of these mechanisms may apply to all coronins, but caution is warranted in applying these ideas to coronins of the Type II and III classes as these proteins have very different localization patterns and may perform different functional roles as outlined below.

\section{F-actin binding}

A defining functional characteristic of Type I coronins is their ability to bind to F-actin. With the publication of the first structure of a coronin in $2006^{8}$, targeted strategies have been employed to identify surface patches of the $\beta$-propeller that engage the actin 
filament ${ }^{11,12}$. In Coro1B, a charged patch on the top surface of the $\beta$-propeller was shown to be critical for high affinity F-actin binding. A single conserved residue in this patch, Arg30, can be mutated to Asp (R30D) and high affinity F-actin binding is lost. This observation has been confirmed by mutating the equivalent residue in Coro1 $\mathrm{A}$ and Coro1C ${ }^{13}, 14$. Interestingly, this residue is not conserved in Type II coronins, suggesting that these proteins may have an alternate actin binding surface with different characteristics ${ }^{11}$. A recent study on budding yeast coronin made similar findings where an extended patch beginning on the top surface of the $\beta$-propeller and extending down one side contains residues that, when mutated, abolished all detectable F-actin binding 12 .

Interestingly, yeast coronin may harbor a second, lower affinity actin-binding site in the coiled-coil domain that participates in inhibiting cofilin activity (see below), however this site has not been mapped at high resolution ${ }^{15}$. It is important to note that a recent study on yeast coronin from another group did not find detectable actin binding for a fragment containing the coiled-coil domain ${ }^{16}$, so further experiments will be required to resolve this discrepancy.

Actin proteins have intrinsic ATPase activity that is triggered by polymerization into filaments ${ }^{17}$. The inorganic phosphate (Pi) byproduct of this reaction is released more slowly than hydrolysis occurs leading to a segment of filament that retains this bound phosphate. Upon phosphate release, the actin filament adopts an ADP conformation that favors depolymerization at the pointed end. Type I coronins appear to have a distinct preference for ATP/ADP+Pi F-actin over ADP-bound F-actin. The affinity of binding F-actin for human Coro1B is approximately 50-fold higher for freshly polymerized actin that is enriched for ATP/ADP+Pi F-actin relative to filaments polymerized from pure ADP-bound monomers ${ }^{11}$. Similar observations have been made for the budding yeast coronin, suggesting that this is a conserved property of Type I-like coronins ${ }^{15}$.

\section{Arp2/3 interactions}

Coronins of the Type I class also interact with the Arp $2 / 3$ complex. This seven protein complex nucleates new actin filaments as branches off of the sides of existing actin filaments at characteristic $\sim 70^{\circ}$ angle. The first hint that coronins interacted with Arp $2 / 3$ was the co-purification of Coro1A with Arp2/3 complex from neutrophils ${ }^{18}$. This idea was confirmed and extended by the finding that budding yeast coronin could bind to the Arp2/3 complex and inhibit its activity ${ }^{19}$. This was the first evidence that Arp2/3 may have protein inhibitors in addition to activators such as proteins of the WASP-family. Human Coro1B also inhibits Arp2/3 nucleation, although this inhibition required high concentration of the protein when Arp2/3 was activated by the VCA fragment of N-WASP alone ${ }^{20}$. This effect has been confirmed by studies using Coro1A, suggesting that all Type I coronins may share this property ${ }^{21}$.

Recently, a new study on yeast coronin found a concentration dependent switch between activating Arp $2 / 3$ nucleating activity at low coronin concentrations and inhibiting it at higher concentrations ${ }^{16}$. This activation at low concentrations was due to a CA-like sequence in yeast coronin's unique region. The in vivo functionality of this interaction was confirmed by the failure to rescue the actin patch defects seen in CRN1 mutants with point mutants that eliminated the CA-like sequence. It is important to note that this CA-like sequence in not conserved in metazoan Type I or II coronins and underlines the caution should be exercised when equating biochemical or biological functions across species.

Cortactin, another factor that binds to Arp $2 / 3$ complex, synergistically activates the complex when added to reactions containing VCA ${ }^{22}$. Interestingly, Coro1B potently inhibits the Cortactin component of this synergistic activation $\left(\mathrm{IC}_{50}=70 \mathrm{nM}\right)$, suggesting that Coro1B acts to inhibit Arp2/3 in a specific way by preferentially counteracting the effect of 
Cortactin ${ }^{23}$. This notion is supported by the finding that simultaneous depletion of both Coro1B and cortactin in fibroblasts can partially ameliorate the lamellipodial phenotypes seen with the single depletion of either protein. In biochemical assays, Coro1B and cortactin also display antagonist behavior. Cortactin promotes the binding of Arp2/3 complex to actin filaments, while Coro1B induces dissociation.

In addition to activating the Arp2/3 complex, cortactin stabilizes branches by inhibiting their spontaneous disassembly ${ }^{22}$. This suggests that one mechanism Coro1B may use to antagonize cortactin and inhibit Arp2/3 complex function is to promote debranching. Using direct visual assays, our group showed that Coro1B indeed promoted debranching in a manner that was antagonized by cortactin ${ }^{23}$. Further evidence for the involvement of Coro1B in debranching came from two-color live cell imaging where bursts of actin polymerization in the lamellipodia were found to be positive for Arp2/3 complex, followed by a subsequent recruitment of Coro1B that persisted as Arp2/3 was leaving the area. This persistent Coro1B localization in the lamellipodia is consistent with the localization of Coro1B to actin branches both in vitro and in vivo. Interestingly, Coro1B appears to alter the branch angle from $72^{\circ}$ to $\sim 80^{\circ}$ both in vitro and in vivo, suggesting that binding of this protein causes structural changes at the branch. Furthermore, Coro1B and Arp $2 / 3$ complex were found to be mutually exclusive at branches in in vitro preparations raising the intriguing possibility that Coro1B can actually replace Arp $2 / 3$ complex at branches to promote actin network remodeling in the middle and rear of the lamellipodium.

\section{Interactions with the ADF/Cofilin pathway}

In addition to regulating Arp2/3 complex, Type I coronins also regulate the ADF/cofilin pathway. The first evidence of this came from genetic studies in budding yeast where mutations in the CRN1 gene were found to genetically synergize with mutations in the cofilin gene (cofl-22) ${ }^{24}$. Recent data indicate that Crn1p and cofilin participate in the turnover of F-actin at patches in yeast, sites of active endocytosis, although cofilin appears to play a more dominant role in regulating actin turnover at these structures 15,25 . Further evidence for the collaboration of coronin and cofilin in actin filament disassembly comes from studies of a reconstitution system of Listeria actin comet tails ${ }^{26}$. In this system, cofilin-based actin disassembly of these tails is greatly enhanced by the presence of Coro1A and Aip1. Although Aip1 had been known for some time to enhance cofilin activity both in vitro and in vivo ${ }^{27}$, the identification of Coro1A was intriguing. Although the structural requirements of Coro1 A for this activity and exact mechanism of enhancement has not been identified, these authors went on to show that actin filaments could depolymerize from the barbed ends in abrupt bursts ${ }^{28}$. Further work will be required to understand this interesting phenomenon.

The exact mechanism of how coronin and cofilin functionally collaborate is incompletely understood and may differ significantly between species. Both full-length yeast Crn $1 \mathrm{p}$ and human Coro1B block the binding of cofilin to freshly polymerized actin filaments that contain a high content of ATP/ADP+Pi actin subunits ${ }^{11,15}$. Deleting the coiled-coil domain in either protein enhances the binding of cofilin to actin filaments under the same conditions $(\sim 1.5$-fold $)$, and in the case of yeast Crn $1 \mathrm{p}$, this mutant was shown to enhance cofilin severing. These data suggest that the coiled-coil domain contains an important determinant of coronin biochemical function with regard to cofilin. However, the $\Delta \mathrm{CC}$ mutant of $\mathrm{Crn} 1 \mathrm{p}$ retains at least partial activity in vivo ${ }^{15}$, while the equivalent mutant in Coro1B is completely defective in rescuing RNAi depletion phenotypes ${ }^{11}$, suggesting that mammalian cells and yeast cells may require different aspects of coronin activity for full biological function. Interestingly, yeast coronin was also shown to enhance the assembly of ADP-actin through a direct severing effect on filaments (thereby creating more ends for assembly) that required only the coiled-coil domain ${ }^{15}$. As yeast actin is known to immediately release 
inorganic phosphate upon polymerization (unlike mammalian actins) ${ }^{29}$, most of the F-actin in these cells should be in the ADP-F-actin state and the activity of Crn1p towards this form of actin may be particularly important for the biological function of this protein. More work will be required to understand the mechanisms involved in these interactions and how they may be the same or different across species.

Another possible mechanism of the collaboration between Type I coronins and cofilin is the interaction between coronins and the activating phosphatase of cofilins, Slingshot ${ }^{20}$. This phosphatase is conserved as far back as insects and activates $\mathrm{ADF} /$ cofilin proteins by dephosphorylating Ser3, thereby enhancing the severing activity of cofilin. Coro1B was shown to be an interacting partner for Slingshot-1L, and to direct targeting of this protein to the lamellipodia. Over-expression of Slingshot-1L in fibroblasts causes a hyper-ruffling phenotype that can be suppressed by the depletion of Coro1B, suggesting that this interaction is functional.

\section{A working model for Type I coronin function}

Taken together, the experiments described above lead to a working model for Type I coronins as coordinating factors between Arp2/3-based branching assembly and ADF/ Cofilin-based filament disassembly (Fig. 2) 15, 20, 23. The overall goal of this function appears to be to enhance the flux of actin through the assembly/disassembly cycle. It is perhaps easiest to describe this coordination in the context of the lamellipodia, a clear site of action for Type I coronins, although these ideas may also apply to other Arp2/3-based actin structures. By limiting the generation of Arp2/3-based branches at the leading edge through blocking the docking of the Arp $2 / 3$ complex on the sides of filaments or promoting debranching, the temporal rate of branch formation can be finely tuned to meet the cell's needs. Also, this mechanism may serve to focus the creation of branches in a spatial compartment near the membrane, possibly to promote productive lamellipodial protrusion. The branch replacement function of Coro1B may serve to create more flexible branches that may aid in the condensation of the network into actin arcs that contribute to stress fibers in the cell. Finally, the enhancement of ADF/Cofilin activity, either directly or through the slingshot phosphatase, promotes the recycling of actin monomers and other components to support continued actin assembly at the front. The coordinate timing of these functions seems to be tied mostly closely to the nucleotide state of the actin filament itself, although other protein co-factors and signaling inputs likely also contribute to this coordination.

\section{Regulation of Type I coronins}

The regulation of Type I coronins is an important and emerging issue in the field. One of the critical missing pieces of the Arp2/3-Cofilin coordination model described above is an understanding of how post-translational modifications regulate this coordination in space and time. The first specific phosphorylation event known to regulate coronin function came from the identification of the phosphorylation of Coro1B on serine 2 by various PKC isoforms ${ }^{30}$. This phosphorylation disrupts the interaction with the Arp $2 / 3$ complex and dephosphorylation by Slingshot-1L enhances this interaction. This effect appears to be conserved in Coro1A where mutations in its serine 2 residue produce similar effects ${ }^{31}$. Recently, another regulatory phosphorylation event of Coro1 A was discovered involving cyclin-dependent kinase 5 (Cdk5) and several sites in the unique region ${ }^{32}$. Proteomic databases (e.g. PhosphoSitePlus; www.phosphosite.org) contain a multitude of putative phosphorylation sites across the mammalian coronin family, so it appears that these proteins are probably the targets of multiple kinase cascades. It will be important to link these events to changes in functional state in future studies. 


\section{Functional analysis of Type I coronins in mammalian systems}

As described above, studies in single cell eukaryotes have provided important insights into coronin function. In this section, we will focus on the significant strides made in the past few years in understanding the function of the mammalian Type I coronins.

Mammalian Coro1A is strongly enriched in cells of the hematopoetic lineage including cells of the innate immune system such as macrophages and neutrophils. This protein localizes to phagocytic vacuoles in human neutrophils and interacts with the p40phox subunit of NADPH oxidase ${ }^{33}$. Recent data indicate that Coro1A participates in the turnover of F-actin coats on zymosan-containing phagosomes in neutrophil cell lines ${ }^{34}$. Circulating neutrophils from patients with cystic fibrosis have elevated levels of Coro1A, and overexpression of Coro1A in neutrophil cell lines results in enhanced resistance to apoptosis ${ }^{35}$. Remarkably, mycobacteria co-opt the phagocytic machinery of macrophages by stabilizing Coro1A localization at phagosomes, which blocks lysosomal delivery by activating the calciumdependent phosphatase calcineurin ${ }^{36,37}$.

In addition to functions of Coro1 $\mathrm{A}$ in the innate immune system, the generation of knockout mice has spurred significant advances in understanding Coro1 A in adaptive immunity particularly with regard to $\mathrm{T}$ cell function ${ }^{31}$. Coro1 A knockout mice are viable and do not display any gross developmental defects. Coro $1 \mathrm{~A}^{-/-} \mathrm{T}$ cells are defective in chemokinemediated migration and impaired in egress from the thymus. Adoptive transfer of Coro1 $\mathrm{A}^{-1-} \mathrm{T}$ cells shows reduction in homing to lymph nodes. $\mathrm{T}$ cells deficient in Coro1 $\mathrm{A}$ show increased basal F-actin content by phalloidin staining and fail to form a uropod in response to chemokine stimulation. Reconstitution of Coro $1 \mathrm{~A}^{-/-} \mathrm{T}$ cells with mutants that disrupt Arp2/3 binding fails to reverse enhanced phalloidin staining, suggesting that Coro1 A may play an inhibitory role to Arp $2 / 3$ in T cells. An intriguing finding is that Coro1A appears to be important for $\mathrm{T}$ cell survival since loss of Coro1 A results in reduced numbers of peripheral $\mathrm{T}$ cells. Interestingly, treatment of Coro $1 \mathrm{~A}^{-1-}$ thymocytes with actin-disrupting drugs partially restores cell survival. A recent report suggests that $\mathrm{T}$ cell survival is independent of coronin effects on actin, however this requires validation by re-expression of Coro1A F-actin-binding mutants ${ }^{38}$.

Several lines of genetic evidence further support the role of Coro1 A in T cell function in vivo. Mice of the Peripheral T cell deficiency (Ptcd) strain exhibit severe defects in cell migration and thymic egress ${ }^{39}$. A glutamic acid to lysine (E26K) mutation in a conserved surface-exposed residue within the $\beta$-propeller domain of Coro1 A has been identified in Ptcd mice. In migrating wild-type T cells, Coro1 A localizes to leading edge protrusions. However, in Ptcd T cells Coro1 A-E26K is mislocalized, and ectopically expressed Coro1 AE26K in fibroblasts also fails to localize to the leading edge. Ptcd T cells exhibit aberrant protrusions, indicating a defect in regulation of the actin cytoskeleton. Surprisingly, purified Coro1A-E26K retains its ability to bind actin in vitro and has higher Arp2/3 inhibitory activity than wild-type Coro1A. Clearly, more work is needed to understand the mechanism of this mutation. In addition to the Ptcd mutation, a nonsense (Q262X) mutation in Coro1A was identified in a lupus-susceptibility gene $L M B 3$, resulting in suppression of autoimmunity ${ }^{40}$. Finally, a human patient has been identified harboring a germline premature stop mutation in Coro1A that leads to a Severe Combined Immunodeficiency (SCID) phenotype ${ }^{41}$.

The ubiquitous expression of Coro1B suggests that it may have a general role in regulating actin dynamics and cell migration. Coro1B depletion reduces neurite outgrowth in PC-12 cells, supporting a role for Coro1B in neuronal plasticity ${ }^{42}$. Coro1B localizes with the Arp2/3 complex to the leading edge of migrating fibroblasts ${ }^{30}$. Recent work from our group 
has further extended our knowledge of Coro1B function. Coro1B is required for whole-cell motility, as depletion of Coro1B in Rat 2 fibroblasts decreases cell speed by $33 \%$ and impairs lamellipodial protrusion dynamics ${ }^{20}$. Fibroblasts depleted of Coro1B exhibit decreased retrograde actin flow and excess generation of free barbed ends at the cell margin. In addition, the activity of cofilin (as measured by phosphorylation state) in Coronin 1Bdepleted cells is reduced by half, likely due to loss of targeting of the cofilin phosphatase slingshot to the leading edge. Electron microscopy reveals altered actin architecture in Coro1B-deficient lamellipodia with more densely branched actin at the cell margin and lack of actin at the rear of lamellipodia compared to controls. The F-actin binding mutation described in the previous section (R30D) impairs its localization to the leading edge and cannot restore motility phenotypes in Coro1B-depleted cells, demonstrating the essential role of F-actin binding for coronin function in vivo ${ }^{11}$. These cell biological phenotypes, as well as the biochemical experiments described above, are consistent with Coro1B modulating actin dynamics in the lamellipodia via both Arp2/3- and ADF/Cofilin-mediated pathways.

Another Type I coronin, Coro1C, is also ubiquitously expressed and localizes to the leading edge of cells ${ }^{43}$. Like Coro1B, Coro1C also co-immunoprecipitates with the Arp2/3 complex, but the functional significance of this interaction remains to be determined ${ }^{44}$. Interestingly, Coro1C interacts in vitro and in vivo preferentially with the GDP-bound form of Rab27a, a member of the Rab-GTPase family involved in regulating membrane trafficking ${ }^{45}$. Based on recent findings, this interaction may also occur between Coro1A and GDP-Rab27a ${ }^{34}$. In addition to the involvement with motility and trafficking, Coro1C may also be involved in tumor metastasis. Expression of Coro1C correlates with degree of malignancy in human glioma, and knockdown of Coro1C in human glioblastoma cell lines impairs cell motility, invasion, and proliferation ${ }^{46}$. In a nude mouse model of hepatocellular carcinoma, Coro1C may be a candidate biomarker as immunohistochemistry has revealed its elevated expression in liver cancer tissues as well as in spontaneous pulmonary metastases 47 .

\section{Not All Coronins Are The Same}

Distinct from the Type I coronins are the Type II \& III coronins (Table 1). Although not widely studied to date, functional mechanisms are beginning to be elucidated for these proteins.

\section{Type II coronins}

Coro2A is a fairly widely expressed Type II coronin isoform that has been implicated in the regulation of focal adhesion turnover events during cell migration ${ }^{48}$. Depletion of Coro2A, which localizes to focal adhesions in MTLn3 adenocarcinoma cells, resulted in impaired focal adhesion turnover and slower cell migration. As with Coro1B, depletion of Coro2A led to decreased ADF/Cofilin activity as measured by Ser3 phosphorylation levels. This decreased ADF/Cofilin activity was responsible for the slow turnover of focal adhesions, as the expression of a constitutively active $\mathrm{ADF} / \mathrm{Cofilin}$ mutant was able to bypass Coro2A depletion and restore focal adhesion turnover and cell migration ${ }^{48}$.

In addition to its role in focal adhesions, Coro2A has also been identified as a component of the Nuclear Co-repressor (NCoR) complex in nuclear extracts of HeLa cells ${ }^{49}$. However, its function here was not known until recently, when a SUMO 2/3 interacting motif (SIM) was discovered at the extreme C-terminal end of Coro2A. This SIM motif was the target of SUMOylated Liver X Receptors, thus uncovering a mechanism for Coro2A in macrophages in the Toll-like receptor inflammation response pathway ${ }^{50}$. Coro2A was a key regulator of NCoR clearance from target gene promoters, an essential step before transcription by Toll- 
like Receptors can occur. Binding of nuclear actin to putative actin-binding residues in Coro2A facilitated its clearance from the target gene promoters, while binding to SUMOylated Liver X Receptors via the SIM blocked this mechanism ${ }^{50}$. Future work will be required to define the ways in which Coro2A participates in functions at focal adhesions and in the nucleus.

Coro2B, a Type II coronin isoform enriched in the nervous system, was first identified as a novel coronin-like protein from cDNA library screens of the human forebrain cortex ${ }^{51}$. Coro2B appears to be involved in reorganization of the neuronal actin cytoskeleton. This was based on its ability to bind actin in vitro and immunofluorescence staining of cultured cells showing localization of Coro2B to stress fibers and focal adhesions, as well as its ability to co-immunoprecipitate with the focal adhesion protein vinculin ${ }^{51}$. These data suggest that Coro2B may also play a role in cell migration, similar to that demonstrated for Coro2 $\mathrm{A}$ at focal adhesions ${ }^{48}$.

\section{Type III coronins}

In addition to the Type I and Type II coronins, most eukaryotes also encode a unique "long" coronin which is quite distinct in both structure and function. This coronin, known as Pod1 in C. elegans and Drosophila or Coro7 in Dictyostelium and humans (Table 1) is remarkably conserved across species. However, the function of POD/Coro7 appears to have changed across species and may have adapted to meet new needs in mammalian systems.

Non-mammalian Pod/Coro7 proteins function in actin-dependent processes. In C. elegans, pod-1 mutations disrupt single cell embryo polarity due to mis-localization of Par proteins ${ }^{52}$. Abnormal vesicular trafficking along with defects in the cellular membrane and eggshell development occur in embryos lacking POD-1, suggesting multiple cytoskeletonlinked roles for POD-1 in C.elegans. Mutation of pod1 in Drosophila causes defects in growth cone guidance ${ }^{53}$. In vitro binding experiments indicate Pod 1 has the ability to crosslink the actin and microtubule cytoskeletons, suggesting an important cross-linking role for Pod1 in the fly nervous system and a possible mechanism for the observed growth cone defects. Dictyostelium DdCoro7 (encoded by the corB gene) accumulates with actin at cell surface projections and binds to F-actin in vitro ${ }^{54}$. Knockout of DdCoro7 led to defects in migration in response to chemotactic stimulus, but a surprising increase in phagocytosis ${ }^{54}$. Double knockout of both the corA and $\operatorname{cor} B$ genes, encoding the Type I and III coronin proteins in this organism, led to more severe phenotypes in most assays ${ }^{55}$.

Human Coro7 localizes to Golgi complex where it plays a role in maintenance of the Golgi morphology and membrane trafficking, however this protein does not apparently interact with the actin cytoskeleton ${ }^{56}$. Targeting of Coro7 to the Golgi membrane is reliant on tyrosine phosphorylation of Coro ${ }^{57}$. Redistribution of Coro7 to the cytosol following treatment with the Src Kinase inhibitor SU6556 implicates Src as the key kinase in this phosphorylation dependent membrane targeting, but further studies of a potential SrcCoronin 7 interaction are needed to confirm this and to enhance our understanding of Coro7s function at the Golgi.

\section{Concluding remarks}

Significant progress has been made in the last few years in our understanding of the coronin family. We have highlighted these advances primarily in the context of mammalian coronins, but it is important to note that there may be species-specific differences in coronin function. The future holds great promise toward uncovering new roles for these fascinating actin-regulatory proteins, however several unanswered questions remain (Box 1). The coronin field will require the application of new techniques to deepen our understanding of 
these proteins. The rapidly developing approach of single molecule imaging, particularly in a multi-color format, should greatly enhance our understanding of the interaction of coronins with actin filaments, the Arp2/3 complex and components of the ADF/cofilin pathway. In addition, new animal models of coronin function will be required to understand how the modulation of actin dynamics contributes to cellular and organismal biology.

\section{Acknowledgments}

We apologize to our colleagues whose work we could not highlight due to length constraints. This work was supported by grants from the NIH (GM083035) and the Howard Hughes Medical Institute.

\section{References}

1. de Hostos EL. The coronin family of actin-associated proteins. Trends Cell Biol. 1999; 9:345-350. [PubMed: 10461187]

2. Uetrecht AC, Bear JE. Coronins: the return of the crown. Trends Cell Biol. 2006; 16:421-426. [PubMed: 16806932]

3. de Hostos EL, et al. Coronin, an actin binding protein of Dictyostelium discoideum localized to cell surface projections, has sequence similarities to G protein beta subunits. EMBO J. 1991; 10:40974104. [PubMed: 1661669]

4. de Hostos EL, et al. Dictyostelium mutants lacking the cytoskeletal protein coronin are defective in cytokinesis and cell motility. J Cell Biol. 1993; 120:163-173. [PubMed: 8380174]

5. Rauchenberger R, et al. Coronin and vacuolin identify consecutive stages of a late, actin-coated endocytic compartment in Dictyostelium. Curr Biol. 1997; 7:215-218. [PubMed: 9276759]

6. de Hostos EL. A brief history of the coronin family. Subcell Biochem. 2008; 48:31-40. [PubMed: 18925369]

7. Stirnimann CU, et al. WD40 proteins propel cellular networks. Trends Biochem Sci. 2010; 35:565574. [PubMed: 20451393]

8. Appleton BA, et al. The crystal structure of murine coronin-1: a regulator of actin cytoskeletal dynamics in lymphocytes. Structure. 2006; 14:87-96. [PubMed: 16407068]

9. Xavier CP, et al. Evolutionary and functional diversity of coronin proteins. Subcell Biochem. 2008; 48:98-109. [PubMed: 18925374]

10. Morgan RO, Fernandez MP. Molecular phylogeny and evolution of the coronin gene family. Subcell Biochem. 2008; 48:41-55. [PubMed: 18925370]

11. Cai L, et al. F-actin binding is essential for coronin 1B function in vivo. J Cell Sci. 2007; 120:1779-1790. [PubMed: 17456547]

12. Gandhi M, et al. Functional surfaces on the actin-binding protein coronin revealed by systematic mutagenesis. J Biol Chem. 2010; 285:34899-34908. [PubMed: 20813846]

13. Tsujita K, et al. Proteome of acidic phospholipid-binding proteins: spatial and temporal regulation of Coronin 1A by phosphoinositides. J Biol Chem. 2010; 285:6781-6789. [PubMed: 20032464]

14. Kimura T, et al. Actin assembly controlled by GDP-Rab27a is essential for endocytosis of the insulin secretory membrane. Arch Biochem Biophys. 2010; 496:33-37. [PubMed: 20138020]

15. Gandhi M, et al. Coronin switches roles in actin disassembly depending on the nucleotide state of actin. Mol Cell. 2009; 34:364-374. [PubMed: 19450534]

16. Liu SL, et al. Mechanism of a concentration-dependent switch between activation and inhibition of ARP2/3 complex by coronin. J Biol Chem. 2011

17. Pollard TD, et al. Molecular mechanisms controlling actin filament dynamics in nonmuscle cells. Annu Rev Biophys Biomol Struct. 2000; 29:545-576. [PubMed: 10940259]

18. Machesky LM, et al. Mammalian actin-related protein $2 / 3$ complex localizes to regions of lamellipodial protrusion and is composed of evolutionarily conserved proteins. Biochem J. 1997; 328(Pt 1):105-112. [PubMed: 9359840]

19. Humphries CL, et al. Direct regulation of Arp $2 / 3$ complex activity and function by the actin binding protein coronin. J Cell Biol. 2002; 159:993-1004. [PubMed: 12499356] 
20. Cai L, et al. Coronin 1B coordinates Arp2/3 complex and cofilin activities at the leading edge. Cell. 2007; 128:915-929. [PubMed: 17350576]

21. Yan M, et al. Coronin function is required for chemotaxis and phagocytosis in human neutrophils. J Immunol. 2007; 178:5769-5778. [PubMed: 17442961]

22. Weaver AM, et al. Cortactin promotes and stabilizes Arp2/3-induced actin filament network formation. Curr Biol. 2001; 11:370-374. [PubMed: 11267876]

23. Cai L, et al. Coronin $1 \mathrm{~B}$ antagonizes cortactin and remodels Arp2/3-containing actin branches in lamellipodia. Cell. 2008; 134:828-842. [PubMed: 18775315]

24. Goode BL, et al. Coronin promotes the rapid assembly and cross-linking of actin filaments and may link the actin and microtubule cytoskeletons in yeast. J Cell Biol. 1999; 144:83-98. [PubMed: 9885246]

25. Lin MC, et al. Overlapping and distinct functions for cofilin, coronin and Aip1 in actin dynamics in vivo. J Cell Sci. 2010; 123:1329-1342. [PubMed: 20332110]

26. Brieher WM, et al. Rapid actin monomer-insensitive depolymerization of Listeria actin comet tails by cofilin, coronin, and Aip1. J Cell Biol. 2006; 175:315-324. [PubMed: 17060499]

27. Ono S. Regulation of actin filament dynamics by actin depolymerizing factor/cofilin and actininteracting protein 1: new blades for twisted filaments. Biochemistry. 2003; 42:13363-13370. [PubMed: 14621980]

28. Kueh HY, et al. Actin disassembly by cofilin, coronin, and Aip1 occurs in bursts and is inhibited by barbed-end cappers. J Cell Biol. 2008; 182:341-353. [PubMed: 18663144]

29. Bryan KE, Rubenstein PA. An intermediate form of ADP-F-actin. J Biol Chem. 2005; 280:16961703. [PubMed: 15536092]

30. Cai L, et al. Phosphorylation of coronin $1 \mathrm{~B}$ by protein kinase $\mathrm{C}$ regulates interaction with Arp2/3 and cell motility. J Biol Chem. 2005; 280:31913-31923. [PubMed: 16027158]

31. Foger N, et al. Requirement for coronin 1 in $\mathrm{T}$ lymphocyte trafficking and cellular homeostasis. Science. 2006; 313:839-842. [PubMed: 16902139]

32. Pareek TK, et al. Cyclin-dependent kinase 5 activity is required for $\mathrm{T}$ cell activation and induction of experimental autoimmune encephalomyelitis. J Exp Med. 2010; 207:2507-2519. [PubMed: 20937706]

33. Grogan A, et al. Cytosolic phox proteins interact with and regulate the assembly of coronin in neutrophils. J Cell Sci. 1997; 110(Pt 24):3071-3081. [PubMed: 9365277]

34. Yokoyama K, et al. Rab27a Negatively Regulates Phagocytosis by Prolongation of the Actincoating Stage around Phagosomes. J Biol Chem. 2011; 286:5375-5382. [PubMed: 21169636]

35. Moriceau S, et al. Coronin-1 is associated with neutrophil survival and is cleaved during apoptosis: potential implication in neutrophils from cystic fibrosis patients. J Immunol. 2009; 182:72547263. [PubMed: 19454722]

36. Ferrari G, et al. A coat protein on phagosomes involved in the intracellular survival of mycobacteria. Cell. 1999; 97:435-447. [PubMed: 10338208]

37. Jayachandran R, et al. Survival of mycobacteria in macrophages is mediated by coronin 1dependent activation of calcineurin. Cell. 2007; 130:37-50. [PubMed: 17632055]

38. Mueller P, et al. Migration and Homeostasis of Naive T Cells Depends on Coronin 1-Mediated Prosurvival Signals and Not on Coronin 1-Dependent Filamentous Actin Modulation. J Immunol. 2011

39. Shiow LR, et al. The actin regulator coronin $1 \mathrm{~A}$ is mutant in a thymic egress-deficient mouse strain and in a patient with severe combined immunodeficiency. Nat Immunol. 2008; 9:1307-1315. [PubMed: 18836449]

40. Haraldsson MK, et al. The lupus-related Lmb3 locus contains a disease-suppressing Coronin-1A gene mutation. Immunity. 2008; 28:40-51. [PubMed: 18199416]

41. Shiow LR, et al. Severe combined immunodeficiency (SCID) and attention deficit hyperactivity disorder (ADHD) associated with a Coronin-1A mutation and a chromosome 16p11.2 deletion. Clin Immunol. 2009; 131:24-30. [PubMed: 19097825]

42. Di Giovanni S, et al. In vivo and in vitro characterization of novel neuronal plasticity factors identified following spinal cord injury. J Biol Chem. 2005; 280:2084-2091. [PubMed: 15522871] 
43. Spoerl Z, et al. Oligomerization, F-actin interaction, and membrane association of the ubiquitous mammalian coronin 3 are mediated by its carboxyl terminus. J Biol Chem. 2002; 277:4885848867. [PubMed: 12377779]

44. Rosentreter A, et al. Coronin 3 involvement in F-actin-dependent processes at the cell cortex. Exp Cell Res. 2007; 313:878-895. [PubMed: 17274980]

45. Kimura T, et al. The GDP-dependent Rab27a effector coronin 3 controls endocytosis of secretory membrane in insulin-secreting cell lines. J Cell Sci. 2008; 121:3092-3098. [PubMed: 18768935]

46. Thal D, et al. Expression of coronin-3 (coronin-1C) in diffuse gliomas is related to malignancy. $\mathbf{J}$ Pathol. 2008; 214:415-424. [PubMed: 18189330]

47. $\mathrm{Wu} \mathrm{L}$, et al. Coronin-1C is a novel biomarker for hepatocellular carcinoma invasive progression identified by proteomics analysis and clinical validation. J Exp Clin Cancer Res. 2010; 29:17. [PubMed: 20181269]

48. Marshall TW, et al. Coronin 2A regulates a subset of focal-adhesion-turnover events through the cofilin pathway. J Cell Sci. 2009; 122:3061-3069. [PubMed: 19654210]

49. Yoon HG, et al. Purification and functional characterization of the human N-CoR complex: the roles of HDAC3, TBL1 and TBLR1. EMBO J. 2003; 22:1336-1346. [PubMed: 12628926]

50. Huang W, et al. Coronin $2 \mathrm{~A}$ mediates actin-dependent de-repression of inflammatory response genes. Nature. 2011; 470:414-418. [PubMed: 21331046]

51. Nakamura T, et al. A neurally enriched coronin-like protein, ClipinC, is a novel candidate for an actin cytoskeleton-cortical membrane-linking protein. J Biol Chem. 1999; 274:13322-13327. [PubMed: 10224093]

52. Rappleye CA, et al. The coronin-like protein POD-1 is required for anterior-posterior axis formation and cellular architecture in the nematode caenorhabditis elegans. Genes Dev. 1999; 13:2838-2851. [PubMed: 10557211]

53. Rothenberg ME, et al. Drosophila pod-1 crosslinks both actin and microtubules and controls the targeting of axons. Neuron. 2003; 39:779-791. [PubMed: 12948445]

54. Shina MC, et al. A Coronin7 homolog with functions in actin-driven processes. J Biol Chem. 2010; 285:9249-9261. [PubMed: 20071332]

55. Shina MC, et al. Redundant and unique roles of coronin proteins in Dictyostelium. Cell Mol Life Sci. 2011; 68:303-313. [PubMed: 20640912]

56. Rybakin V, et al. Coronin 7, the mammalian POD-1 homologue, localizes to the Golgi apparatus. FEBS Lett. 2004; 573:161-167. [PubMed: 15327992]

57. Rybakin V, et al. Molecular mechanism underlying the association of Coronin-7 with Golgi membranes. Cell Mol Life Sci. 2008; 65:2419-243. [PubMed: 18581049] 


\section{Box 1}

Outstanding questions

1. Type I coronins affect actin dynamics in the lamellipodium and in other structures. What are the relative contributions of Arp2/3 vs. cofilin pathway regulation? This question will require detailed understanding of the mechanisms involved and specific mutations that selectively affect these pathways to resolve.

2. What is the functional consequence of the replacement of Arp $2 / 3$ complex at actin branches by Coro1B? Although the notion of branch replacement will require confirmation by other approaches, the (presumably) more flexible branches created by this reaction may allow actin filaments born in the Arp2/3based network to contribute to other F-actin structures in the cell.

3. Oligomerization of coronins through their coiled-coil domains appears to be critical for interacting with some binding partners and regulating their biochemical activity. How does the coiled coil domain contribute to coronin function? If it is merely an oligomerization domain, it should theoretically be able to be replaced by a synthetic oligomerization sequence. Based on a recent study where the coiled coil domain of yeast coronin was replaced with such a synthetic trimerization domain, this appears to be the case for coronin's ability to modulate Arp $2 / 3$ activity in vitro ${ }^{16}$. It will be interesting to see if this synthetic construct is also able to regulate cofilin activity and whether it is functional in vivo.

4. What is the relationship between Coro2A function at focal adhesions in the cytoplasm and its role in controlling gene expression in the nucleus through its interaction with NCoR? There is precedent for nucleo-cytoplasmic shuttling of focal adhesion proteins such as those of the zyxin family, so it is possible that type II coronins do something similar. A more thorough understanding of the mechanism of Coro2A localization in various cell types will be required to approach this question. 


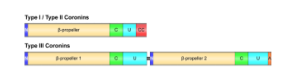

Figure 1.

Schematic of coronin structural domain arrangement.

Type I and Type II coronins share similar structural organization, including an $\mathrm{N}$-terminal extension (N), a $\beta$-propeller, a $\mathrm{C}$-terminal extension (C), a unique region (U) and a coiledcoil domain (CC). In Type I and type II coronins, the coiled-coil domain is involved in coronin oligomerization. Type III coronins lack a coiled-coil domain but instead comprise two $\beta$-propellers (with $\mathrm{N}$ - and $\mathrm{C}$-terminal extensions) and an acidic region (A). 


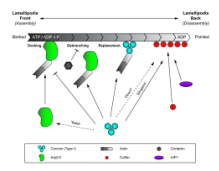

Figure 2.

Integrated model of Type I coronin function

Coronin is a coordinating factor between Arp2/3-based actin assembly and cofilin-mediated disassembly. In the context of lamellipodia, at the leading edge the Arp2/3 complex promotes actin assembly by binding existing actin filaments and nucleating new actin branches. Coronin limits Arp2/3-dependent actin branches through inhibition of Arp2/3 docking or facilitating debranching, a function which is antagonized by cortactin. Coronin can replace Arp2/3 at actin branches and create more flexible branches. At the lamellipodia rear, cofilin facilitates actin disassembly. Coronin enhances the activity of cofilin either directly or by targeting the slingshot phosphatase. In addition, coronin may synergize with AIP1. Dashed lines indicate interactions that have only been seen in one species or require further validation by functional studies in vivo. 


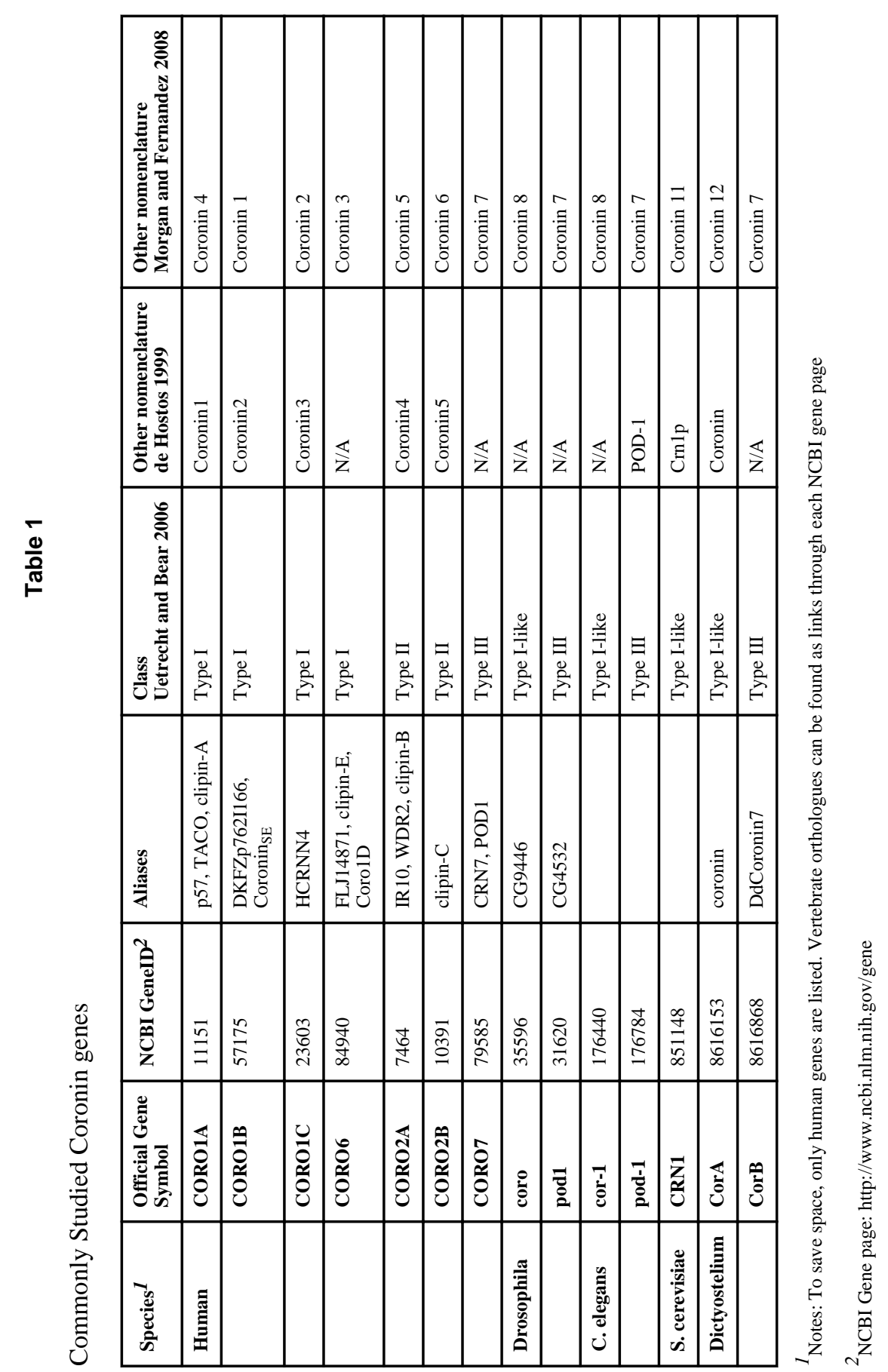

Trends Cell Biol. Author manuscript; available in PMC 2012 August 1. 